J. Environ. Sci.

Institute of Environmental Studies and Research - Ain Shams University

\title{
DESIGN OF A SENSOR NETWORK NODE FOR AIR QUALITY MONITORING IN NUCLEAR INSTALLATIONS
}

\author{
Essam I. Sobeh ${ }^{(1)}$; Noha S. Donia ${ }^{(2)}$; Amr M. Abd El Salam ${ }^{(1)}$ \\ and Mohamed N. ELSayed ${ }^{(1)}$ \\ 1) Egyptian Nuclear and Radiological Regulatory Authority (ENRRA) \\ 2) Institute of Environmental Studies and Research, Ain Shams University.
}

\begin{abstract}
Nowadays, the Sensor Networks offer many benefits to the environment and humanity, starting with monitoring environmental phenomena, monitoring and control of industrial facilities/processes (especially in Nuclear Power Plants, NPPs) and following up on the health status of the elderly. In nuclear field, radiation monitoring systems and networks are among the most important systems used to the assessment of nuclear safety and radiation protection processes. Furthermore these networks are used as inspection tool of occupational radiation protection to predict any states of diffraction or deviation of the correct operating factors to maintain the integrity of the internal or the surrounding environment of the nuclear facilities.

This paper presents a prototype (hand made prototype) of a sensor network node $(\mathrm{SN})$ for air quality monitoring system which can be used indoors or outdoors. The proposed SN is based on the AVR microcontroller and is characterized by the small size, low power consumption, simplicity, and lower cost. The microcontroller, $\mu \mathrm{C}$, performs specific tasks, transfers data, and controls the functionality of the SN. It is often used as the brain in many embedded systems because of its great abilities, flexibility, ease of programming, low cost, and low power consumption. So that it was a compelling argument to use $\mu \mathrm{C}$ in the design of the sensor network.
\end{abstract}

Keywords: Nuclear Power Plants (NPPs), Sensor network node (SN), Microcontroller AVR- $\mu \mathrm{C}$, Breadboard circuit, air quality monitoring. 


\section{INTRODUCTION}

When talking about Radiological Sensor Networks (RSNs), we mean these networks that facilitate the study of fundamental processes and the development of hazard response systems. They have evolved via many stages from passive logging systems that require manual downloading for sensors' data, into 'intelligent' sensor networks that comprise a sensing network of automatic SNs and communications protocols which actively transfer their data to a main or server computer [Robert A. et al. (2014)].

Nowadays there are many technologies of Sensor Networks that deploy many small sensor devices fixed on the network nodes to sense and measure the environmental phenomena or industrial factors. The primary function of the node will be to monitor the environmental physical quantities (air quality) and send them to the base station [Gaurav Pratap Singh. (2014)]. the brain of each $\mathrm{SN}$ is the $\mu \mathrm{C}$ which processes readings from its own sensors.

Over the last decade, many sensor networks, wired or wireless for monitoring systems have been extensively developed and studied for numerous diverse applications. Sensor networks are environmental centric with nodes embedded within the environment (may be harsh environment of NPPs) in a ad hoc fashion. Currently in the wired networks domain, the main problem is the complexity of data and power cabling. On the other side in wireless domain there are many common problems. Wireless nodes are not tethered or connected to a fixed power source and use internal batteries for power. So, energy conservation is a major issue or problem for wireless sensors nets. In the same time, the wireless networks suffer of the level of data security beside the Wi-Fi signal weakness and instability. 


\section{The Goal:}

The ultimate goal is to design and establish an efficient, simple and cost less monitoring $\mathrm{SN}$ that can be used in monitoring the air quality levels in nuclear installations. In addition, the proposed SN can be used to achieve an ease and efficient computerized monitoring system to predict the environmental deviation states and the assessment of emergency cases to provide a high level of safety for human and the environment (particularly in NPPs facilities). By considering all these issues, in this research we have designed a sensor network node that overcomes some of the previous mentioned drawbacks of the wired and wireless monitoring networks.

\section{Experimental Design and methodology:}

In this prototype system, we develop a $\mathrm{SN}$ to monitor and measure the air purity to provide necessary data for the network operator/administrator. We used three air quality sensors with type MQ-135 [www.olimex.com (2011)]. This sensor is low-cost, analog type, high sensitivity and durability. The sensors are connected to a breadboard electronic circuit which we assembled as handmade. In this research we used the AVR 8-bit $\mu \mathrm{C}$ (Alf-Egil and Vegard RISC processor) [James F. K. and Harold T.(2013), www.avrtutorials.com (2016)]. This IC chip is easy interfacing and programming (in C language) to collect the sensors readings or values. Not only the sensors' readings are displayed on the $\mathrm{PC}$ monitor, but also we can get a data graph or a data list as a computer file that could be stored and analyzed later. 
The remaining of the paper is organized as follows;

Section-I demonstrates the basic concept and importance of the $\mu \mathrm{C}$ and its characteristics. In section-II we demonstrate the AVR 8-bit $\mu \mathrm{C}$ features and architecture. Section-III describes the methodology used in implementation of the $\mathrm{SN}$ and illustrates its design and the electronic breadboard. Section-V explains the concept of air quality and how to use the air quality sensor and its interfacing with the SN. Finally Section-VI is a conclusion and a discussion of the results we had got from the sensor readings of the monitoring node and suggests some future extensions of the proposed prototype.

\section{Material and Tools:}

In this research, we used an appropriate set of electronic elements; on the top of them is the microcontroller from AVR family, MQ-135 sensor to measure the air purity and PC / Laptop computer to display the results and measurements. Other

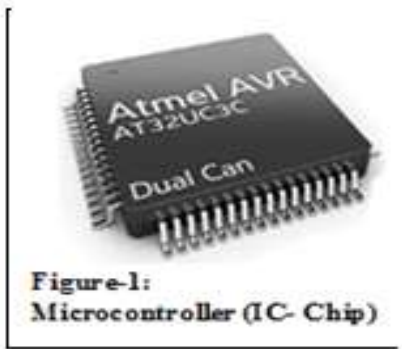
associated electronic components such as capacitors, resistors, $16 \mathrm{MHz}$ oscillator, LEDs and a voltage regulator 7805 were also used. Of course to complete the design of our system, we used the soldering iron and a small piece of Printed Circuit Board (PCB) to assemble the prototype of the proposed sensor network node.

\section{Microcontroller $(\mu \mathrm{C})$ :}

The microcontroller is the brain of the SN. It is a small or tiny integrated circuit IC-chip (figure-1) that is programmed to do a specific task. It can be 
considered as a small computer or micro-computer having processor core, storage elements, and programmable input/output modules. For tremendous features and benefits, the design of the proposed system depends on the features and advantages of the $\mu \mathrm{Cs}$ to establish the desired intelligent sensor network. Nowadays although there are other alternatives of $\mu \mathrm{Cs}$ that can be used such as; general purpose computer microprocessor and FPGAs (FieldProgrammable Gate Array), the $\mu \mathrm{Cs}$ are often used in many embedded systems because of their ease of programming, low power consumption, flexibility to connect to other devices and low cost. Although many $\mu \mathrm{C}$ families are available in market, there are four most renowned families; those are Intel 8051, PIC (Peripheral Interface Controller) from microchip Inc., AVR $\mu$ Cs, and ARM (Advanced RISC Machines Inc.). Where there are some cons of Intel and PIC families so that there were two options to use AVR $\mu \mathrm{C}$ or ARM $\mu \mathrm{C}$. Although ARM has good characteristics but AVR $\mu \mathrm{C}$ has an important feature that AVR 8-bit $\mu \mathrm{C}$ has wider operating voltage range $(2.7 \mathrm{v}$ 5.5v) than ARM $\mu \mathrm{C}$, which is useful for dealing with different logic devices [www.microchip.com (2010)].

I. AVR 8-bit $\mu \mathrm{C}$ Architecture: The first and foremost criterion in choosing a microcontroller is that it must meet the task at hand efficiently and cost effectively [Muhammed A. M. and Sarmad N. (2011)]. This AVR $\mu$ C is 8bit RISC-based $\mu \mathrm{C}$ which has $32 \mathrm{~KB}$ ISP (In-System Self-Programmable) flash memory with read-while-write capabilities. It is a low power CMOS microcontroller and by executing powerful instructions in a single clock cycle, it achieves throughputs approaching $1 \mathrm{MIPS} / \mathrm{MHz}$ allowing the 
system designer to optimize power consumption versus processing speed (Active mode $0.3 \mathrm{~mA}$ and Power-down Mode $0.1 \mathrm{~mA}$ ). The core combines a rich instruction set with 32 general purpose working registers. The internal components of typical AVR 8-bit $\mu \mathrm{C}$ are shown in figure-2.

The AVR was one of the first $\mu \mathrm{C}$ families to use on-chip flash memory for program storage, as opposed to EPROM (Erasable Programmable ReadOnly Memory) used by other $\mu \mathrm{Cs}$ at that time. Also, allowing two independent registers to be accessed in one single instruction executed in one clock cycle, the architecture is more code efficient while achieving throughputs up to ten times faster than conventional CISC $\mu$ Cs (Complex Instruction Set Computing).

Figure-2:

AVR 8-bit microcontroller Archeticture

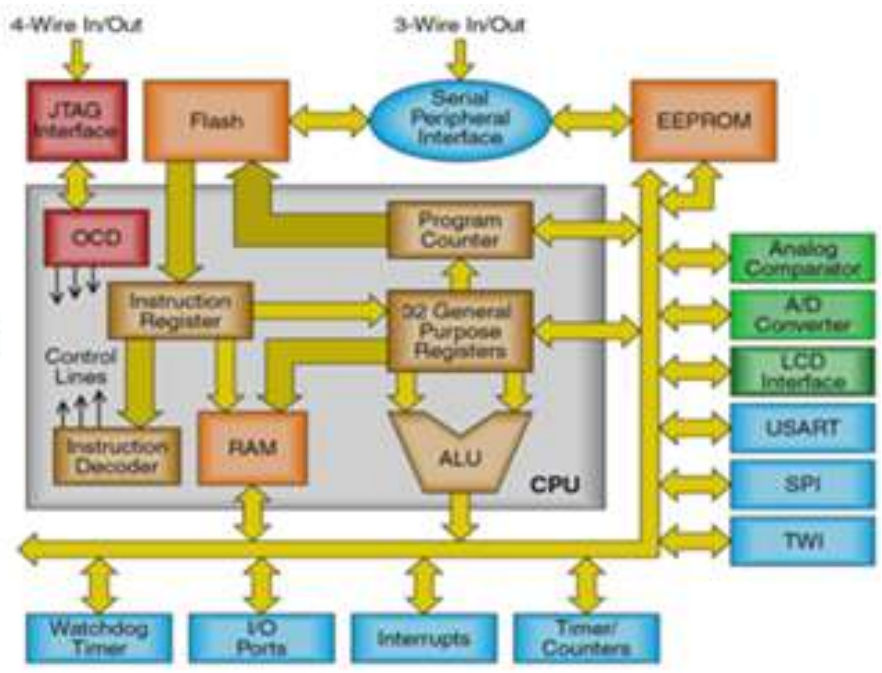

\section{Implementation of the Sensor Network Node:}

A. The Sensor Network Node Breadboard Layout: By the first decade of the 2000s, nobody would seriously consider designing anything other than the very simplest consumer electrical device without the use of some kind 74

Vol. 45, No. 3, March 2019 
of microcontroller [Alan T. (2012)]. In NPPs, system monitoring dose rate is one of technical systems supporting decision-making in emergency situations. These decision-making systems depend on the design of the SN and consequently the microcontrollers. So that the $\mathrm{SN}$ is very important block where it comprises a group of sensors (may be with different types) and other electronic components, communication ports / peripherals and the power means [Tanuska P., et al. (2014)]. In this section we explain the practical work and procedures of building the proposed SN. The schematic diagram of the proposed node based on the AVR 8-bit $\mu \mathrm{C}$ is shown in figure-3(a) and the electronic breadboard is as shown in figure-3(b).

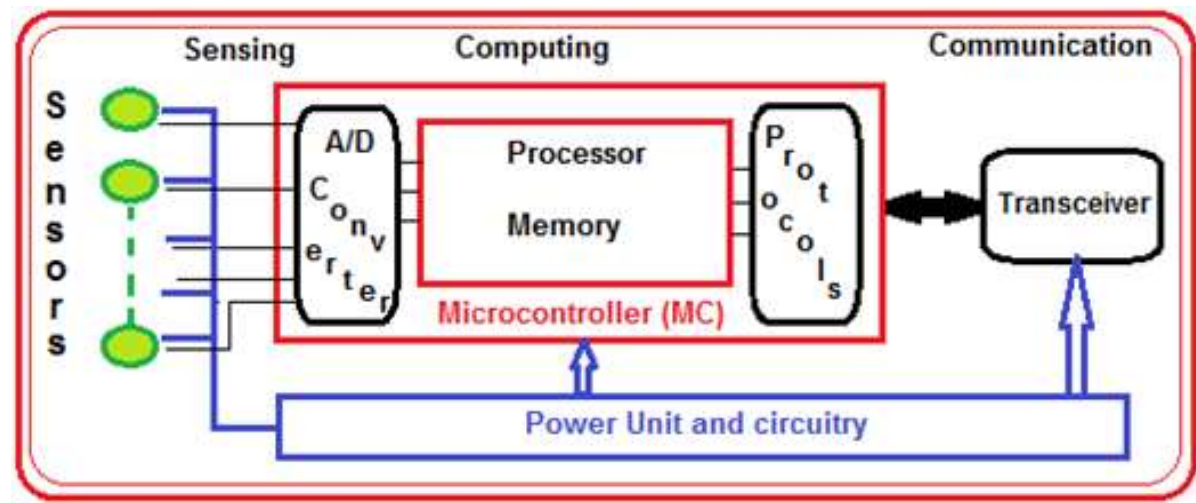

Figure-3(a): Sensor Network Node Schematic Diagram 


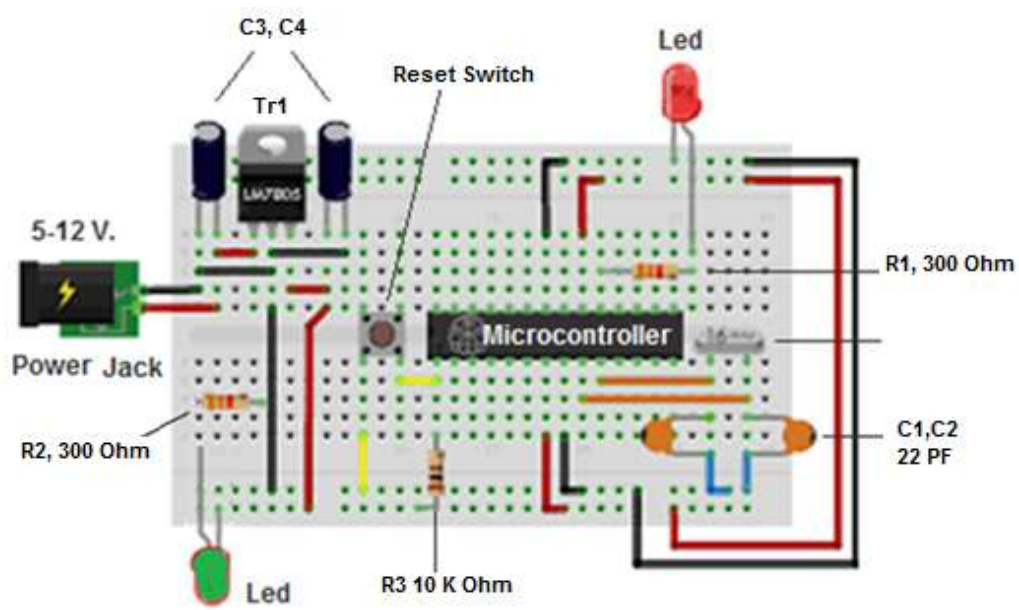

Figure-3(b): Sensor Network Node Breadboard

Advances in communication and electronics technologies have made it possible to build ad hoc inexpensive SN consuming little energy (about 20 mA.), a modest amount of memory, and a small board size. A typical node is comparable in size to two AA batteries or one match's box due to using the tinny 8-bit AVR $\mu \mathrm{C}$ and could be linked with other nodes (or motes) in the network [Tobgay S., et al (2012)]..

B-List of components: The main components and their functions are:

- AVR 8-bit Microcontroller: The desired SN depends on the AVR $\mu \mathrm{C}$ and its powerful capabilities, so that AVR- $\mu \mathrm{C}$ was a good choice for the required tasks of the proposed node.

- Crystal oscillator: $16 \mathrm{MHz}$ oscillator to get external clock for the AVR $\mu \mathrm{C}$.

- C1, C2 Two capacitors 22 pico: for the supplying the external clock.

- R1,R2 Two Resistors $300 \mathrm{ohm}$ : They are used to serially connected to the two LEDs to drop the +5 voltage. 
- R3 Resistor 10Kohm: this pull-up resistor is used to prevent the chip from resetting itself during normal operation.

- Two colored LEDs (green and red): One of the two LEDs (green) is used to test the power supply circuit and the other LED (red) is used to test or check the first operation (readiness) of the node breadboard (The long leg or the LED anode connects to the chip pin-13 and the short leg or the cathode connects to the $300 \mathrm{ohm}$ resistor going to ground).

- Push-Pull button (Reset): By adding the small tactile switch, we can reset the $\mu \mathrm{C}$ chip whenever to prepare the chip for uploading a new program.

- Tr1 Transistor 7805: It is a voltage regulator to deliver a stable dc.5V.

- C3, C4 Two capacitors: to keep the voltage levels of the dc. 5V.

- Power adaptor jack: for input power ranged from 5 to $12 \mathrm{dc}$. Volts.

Now after constructing the node breadboard we move to another practical step that is the node test and first time operation.

\section{C-Sensor Network Node Testing and First Time Operation:}

Currently it is simple for developers who come from other software fields and even for the non-coding community to develop microcontroller-based hardware applications [Pratik D. (2015)]. To test or check the breadboard of the SN we used the open source software AVR-IDE (Integrated Development Environment) that runs on a PC computer to upload the computer code designed to test the physical board [Kimmo K. and Tero K. (2014)]. After completing the code uploading process and when powering the node board, we saw the green LED emitting light that denoting the power is OK and at the 
same time the red LED was blinking denoting that the programming process and the breadboard is well operating as shown in Figure-4(a).

Also to check the Input / Output pins of the $\mu \mathrm{C}$, we connected additional seven LEDs to the digital pins (pin 6 to pin 12) and after uploading the test code, the seven LEDs were good functionality as shown in Figure-4(b) and hence everything was good
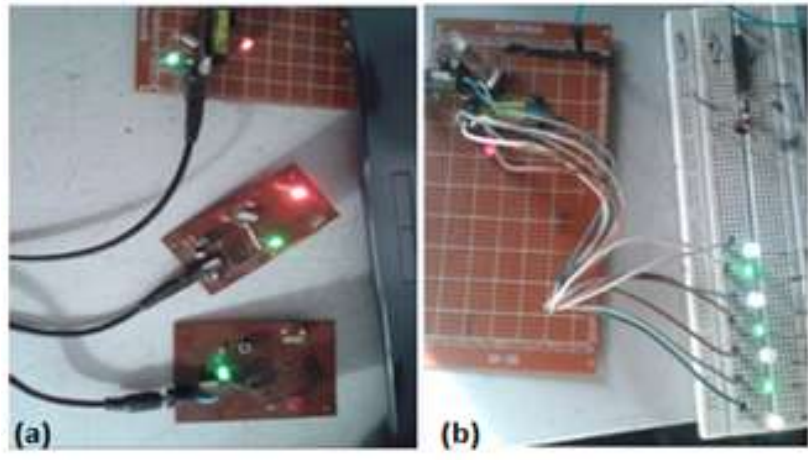

Figure-4: Node Breadboard Testing and the SN breadboard was ready for programming and operating. At last we compared the power consumption of our prototype, which was about $2 \mathrm{~mW}$ against the original/used board which consuming about $60 \mathrm{~mW}$. This gives our model more preference and excellence than the used one.

\section{Air Pollution / Air Quality Monitoring:}

The selection of sensors especially for students starting a project may be a difficult task and can waste a significant amount of time on searching internet [Subhas C. M. (2013)]. There are various types of air pollution and quality sensors, the majority of them focuses on five components or substances; ozone, particulate matter, carbon oxide (mono, dioxide), sulfur dioxide, and nitrous oxide. These sensors are electrochemical gas sensors types which detect and monitor the presence of air pollution in the surrounding or ambient area. Currently these sensors are becoming more affordable and more widespread throughout the various applications and 
systems. Furthermore these sensors, can then, in turn, help in measuring the spatiotemporal coverage and variety of chemical species, and empower individuals and communities to better protection of their exposure environments from risks and the air pollution. In the previous section we have implemented and tested a node breadboard. In this section we are going to interface three air quality sensor modules (MQ-135) with AVR $\mu \mathrm{C}$ to measure the purify level of the air and see some relevant readings on the PC monitor.

\section{V.I. What is MQ-135 gas sensor and how does it work?}

MQ-135 module is widely used in air quality monitoring systems indoors/outdoors and is suitable for detecting of carbon oxides $\mathrm{CO}, \mathrm{CO} 2$, nitrous oxide NOX, ammonia gaseNH3, sulfur dioxide $\mathrm{SO}$, alcohol, Benzene, smoke, etc. The sensor-Kit or module consists of a steel exoskeleton under which a sensing element is housed. The main chip is LM393 and the probe is MQ-135 gas sensing probe. This sensing element is subjected to current through connecting leads. This current is known as the heating current of the sensor through it. When the gases/pollutants are coming close to the sensing element, it ionized and absorbed them. Then the sensing element resistance changes which alters the value of the current going out of it.

\section{V.II. Air Quality Measuring Unit}

There are different methods for measuring gases like carbon dioxide; the term concentration is generally used to describe the amount of gas by volume in the air. The two most common units are PPM (parts-per-million), and the 
percent concentration. Parts-per-million is the ratio of one gas to another. For example, 1,000 ppm of $\mathrm{CO} 2$ means that if we could count a million gas molecules, 1,000 of them would be of carbon dioxide and 999,000 molecules would be some other gases. When you start counting over 10,000ppm, most scientists and manufacturers change from ppm to percent concentration. So instead of describing a 10,000ppm CO2 sensor, we talk about a $1 \% \mathrm{CO} 2$ sensor instead. In other words, $1 \mathrm{ppm}=0.0001 \%$ gas. Resistance value of MQ-135 changes according to various kinds and various concentration gases. So, when using this component, sensitivity adjustment is very necessary. We recommend that to calibrate the detector for 100ppm NH3 or 50ppm Alcohol concentration in air and use value of Load Resistance that ( RL) about $20 \mathrm{~K} \Omega$. MQ-135 operates in the range of 2.5 to 5.0 volt and with adjustable sensor sensitivity, the typical sensitivity characteristics for several gases are: 10:300 PPM for Alcohol / Ammonia (NH3) and 10:1000 PPM for Benzene.

As shown in figure-5 (a), (b), we used three MQ-135 sensors modules and connected them to the proposed SN to measure the purity of ambient air and display the relevant sensors' values on the monitor or store them (to be analyzed later) in the PC computer. 


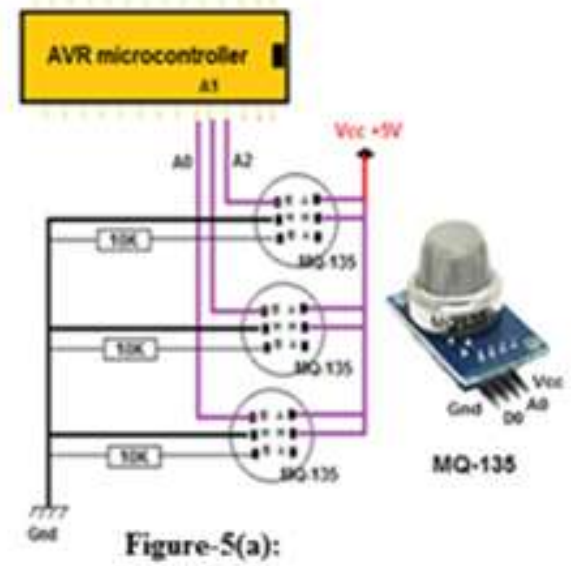

Circuit Diagram of Air Quality Seasor Node

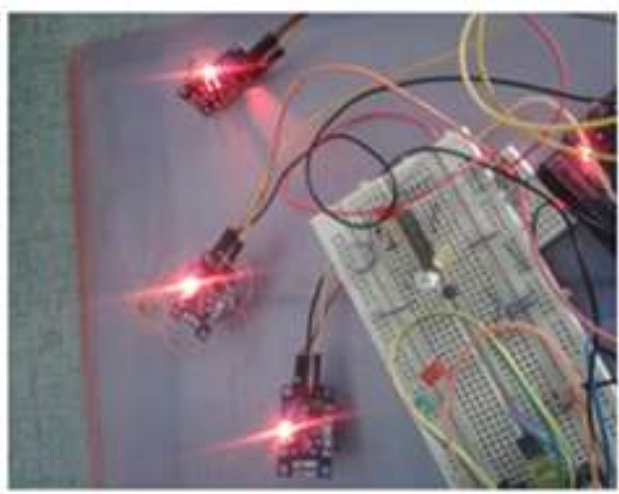

Figure-5(b): Air Quality Sensor Node

After the uploading of the designed code (Air Quality Code) is done, the relevant readings of the sensors were displayed on the PC monitor (Figure-6).

\section{Air Quality Code:}

int sensor1Value;//analog pin(A1),

int sensor2Value;//analog pin(A2)

int sensor3Value;//analog pin(A3)

void $\operatorname{setup}()\{$

pinMode(13, OUTPUT); //pinMode( 0, INPUT); //for digital pin0 \}

Serial.begin(9600);

$\operatorname{void} \operatorname{loop}()\{$

sensor1 = analogRead(1); // read three analog input pins

sensor $2=\operatorname{analogRead}(2)$;

sensor3 = analogRead(3);

Serial.print(" AQS1 - Value is: ");

Serial.print(" AQS2 - Value is: "); 
Serial.print(" AQS3 - Value is: ");

//delay(2000); // wait for next reading

if ((sensor1Value-60)>30 or (sensor2Value-60)>30 or(sensor3Value-

$50)>30)$

$\operatorname{delay}(1000)$;

else $\{$ digitalWrite $(13, \mathrm{LOW}) ;\}$

\section{Conclusion and Results:}

In this paper, we built a prototype of a $\mathrm{SN}$ based on easy-to-use AVR $\mu \mathrm{C}$ board. The proposed node prototype is simple, small size, ease of programming, low power consumption, and low cost. We considered the air quality monitoring application to demonstrate the proof-of-concept of the proposed monitoring system. The collected relevant sensors data can be displayed on the monitor or stored into the PC computer and retrieved later for analysis.

Figure-6 shows that the proposed SN works well and the sensors measure the values or levels of air purity (these readings are taken on the Laptop display in March last year.). Also the read values are for the normal state of the air and with exposure to a source of combustion or carbon dioxide; the microcontroller produces an audible and a visual warning for the responsible for making the necessary decision when critical or unusual conditions occur. Furthermore, it could be to connect more different types of sensors to measure more than one environmental factor of heat, pressure, humidity, emission of gases and air purity...etc on only one node at the same time. 
J. Environ. Sci.

Institute of Environmental Studies and Research - Ain Shams University

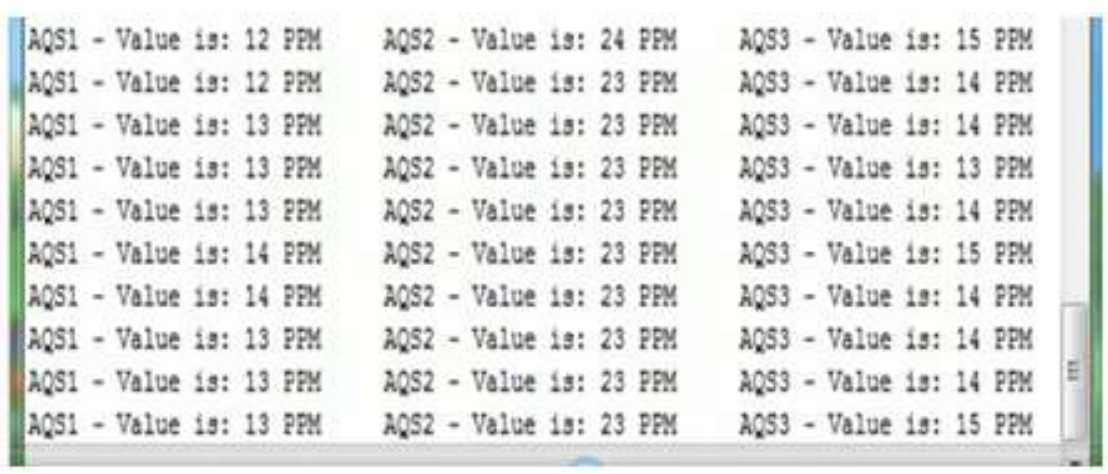

Figure-6: Air Quality Measurements and Values

Extensions of our current work include an extension from a single $\mathrm{SN}$ to multi and different sensors node which will be useful for deploying sensor networks in large areas indoors and outdoors. This sensor network node will be the pulp or the core of environmental and radiation monitoring network. Furthermore there are other new characteristics of the AVR- $\mu \mathrm{C}$ that can be benefited in the future to add a lot of great abilities and capabilities to the proposed sensor network.

\section{REFERENCES}

Alan T. (2012): Practical AVR Microcontrollers Games, Gadgets, and Home Automation with the Microcontroller Used in the Arduino, Book, ISBN-13 (pbk): 978-1-4302-4446-2.

Gaurav P. S. (2014): Designing Of A Microcontroller Based Multi-Sensor System, A Master of Technology Thesis, Department of Electronics \& Communication Engineering, National Institute of Technology, Rourkela-India, Roll No: 212EC3162.

James F. K.; Harold T. (2013): Arduino Adventures: Escape from Gemini Station, Book, Apress, ISBN 978-1-4302-4605-3. 
Kimmo K. ; Tero K. (2014) Getting Started with Sensors,

Book, Maker Media, ISBN: 978-1-449-36708-4.

Muhammed A. M.; Sarmad N. (2011): The AVR microcontroller and embedded systems using assembly and $C$, Book, ISBN-13:978-013-800331-9, Pearson Education Inc.

Pratik D.. (2015): Python Programming For Arduino, Book, Packt Publishing Ltd., ISBN 978-1-78328-593-8.

Robert A. S.; Stephen K. A. (2014): Design and Development of an Efficient and Cost-Effective Microcontroller-Based Irrigation Control System to Enhance Food Security, International Journal of Electrical, Robotics, Electronics and Communications Engineering Vol:8 No:8, 2014.

Subhas C. M. (2013): Intelligent Sensing, Instrumentation and Measurements, Book, Massey University (Turitea), ISBN 978-3642-37026-7, Springer.

Tanuska P., A.; Elias; Vazan P.; Zahradnikova B. (2014): The Nuclear Power Plant Environment Monitoring System through Mobile Unit, Book, World Academy of Science, Engineering and Technology International Journal of Computer, Information, Systems and Control Engineering Vol:8 No:12.

Tobgay S.; Aalborg; Olsen R.L.; Prasad R. (2012): The effect of information access strategy on power consumption and reliability in wireless sensor network, 2nd IEEE International Conference on Parallel, Distributed and Grid Computing, Solan, ISBN: 978-1-4673-29224

www.olimex.com/Products/Components/Sensors/SNSMQ135/resources/SNS-MQ135.pdf, (2011).

Www.avr-tutorials.com/general/microcontrollers-basics, (2016).

www.microchip.com/wwwAppNotes/AppNotes.aspx?appnote=en591472, (2010). 


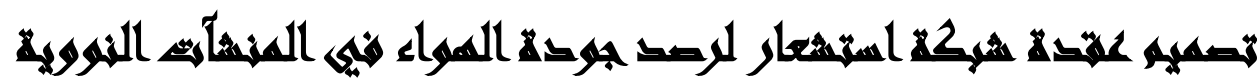

[؛]

$$
\begin{aligned}
& \text { عصام إبراهيم صبيح(')- نهى سمير دنيا(؟)- عمرو محمد عبد السلام (') }
\end{aligned}
$$

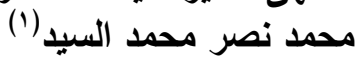

() هيئة الرقابة النووية والإشعاعية(ENRRA (r) معهد الدراسات والبحوث البيئية، جامعة عين

\section{المستطلس}

في الوقت الحالي تقدم شبكات الاستشعار العديد من الفوائد للبيئة والإنسانية، بدءاً بمراقبة

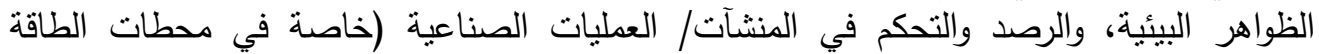

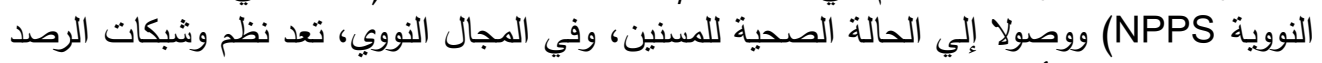

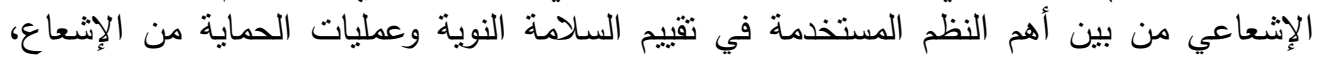

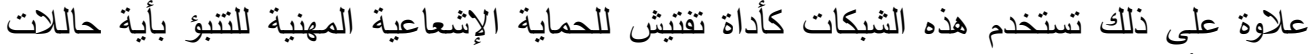
انحراف أو حيود لعوامل التتغيل الصحيحة للحفاظ على سلامة البئة الداخلية والبيئة المحيطة لائة الئة

$$
\text { بالمنشت النورية. }
$$

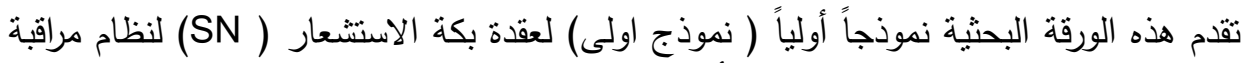

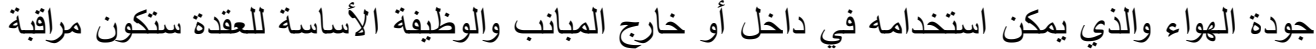

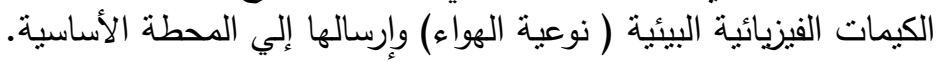
تستتد SN المقترحة علي المتحكم

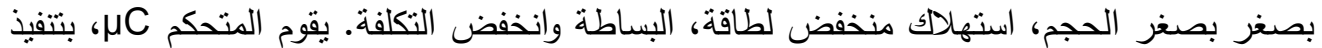

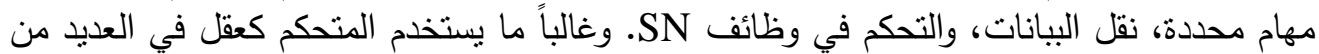

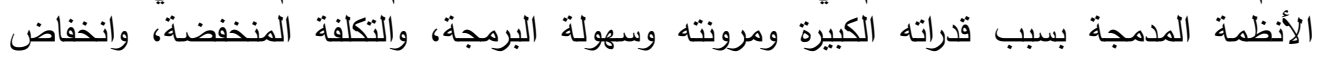
استهلاك الطاقة، لذا كانت حجة مقنعة لاستخدام MC في تصميم عقدة الاستتعار المقترحة. الكلمات الدالة: محطات القوى النووية، عقدة استشعار، متحكم AVR، دائرة الكترونية أولية، رصد فئة 